\title{
Designing a subway station for your campus: Case of transit architecture elective at AGÜ
}

\author{
Özgür Öztürk*
}

\begin{abstract}
Transportation planning and design had been a major concern from the urban planning perspective. Various means of transportation have shaped our cities and landscapes for ages and by looking at transportation buildings from an architectural perspective one can see that existing studies focus on the building performance of the transportation buildings or the history of them. Consequently, transportation building design is an important concern that should be addressed from multiple perspectives. Starting from 2019-2020 Fall Semester, Abdullah Gül University Department of Architecture started a new elective course ARCD 110 Transit Architecture, focusing on this issue. While the main intention of the course is to develop a critical view on the existing prescriptive design methods related to the transportation buildings and their environment, students are expected challenge these discussions at their final projects. In order to develop a critical view on the existing design methods, a considerable part of the class focuses on the design guidelines and typologies of the buildings along with the history of the selected building types. In parallel, student presentations showing different examples throughout the world to inspect different design approaches as well as to start debates regarding various debates around design, global world, awards in architecture, and symbolism in architecture. Afterwards, the class turns into a discussion environment focusing on design issues not only related to transportation buildings but also to the rest of the design environment which they might encounter in the future. these discussions start from multimodal and micro mobile transportation possibilities followed by the personal space as a design parameter. These arguments are followed by sustainability from triple bottom line perspective and the possibilities of different technologies and their effect on the transportation related buildings. Meanwhile, they also experiment with simulation tools to test their design cases in different conditions. After the discussions and the debates students are tasked to design a subway station in front of their campus for a final project. After four semesters, this paper will present the aim of the course, the class structure, projects and the findings of the course with selected examples from the course students to its readers.
\end{abstract}

Keywords: transportation, station design, elective course, transit architecture, infrastructure

\section{Introduction}

Starting with the first railway between Liverpool and Manchester in 1830, architects have deal with different aspects such as the birth of urbanism, shift of population from counties to the cities, 
and a new building type; stations. Along with the first examples of the railway stations, we have started to build different transportation buildings for various vehicles from simple bus stops to huge airports and even airship hangars. These buildings create an exterior image and outstanding profile not only to its users but also to its by-passers acting as a different version of Lynch's (Lynch, 1960) landmarks. Even by looking at the seven wonders of the ancient world, the Great Lighthouse of Alexandria and the Colossus of Rhodes, are edifices that reflect the importance of transportation and connection to other cities in human history. Until the 19th century, cities were in more walkable extents due to fundamental logistic reasons (English, 2019). Cities along the sea, lakes, or rivers used them for transloading only, while moving inside the city was limited by the capacities of the local means of transportation (Vuchic, 2007). By the industrial revolution and the steam-powered railroad networks, one can see that both in inter-city and inner-city scales, connectivity transformed the landscape dramatically. For example, the shift of the population from rural areas to cities commuting for work in metropolises became a daily activity, and transportation-related buildings have turned into important "gates" that greet their users to the city and signs of political power trying to overshadow the function of the building. Currently, one can hardly imagine a settlement isolated from the world without any means of transportation. However, one of the thoughtprovoking notions in this context is the common misconception where the design of an underground transportation building as an infrastructure project is considered an "engineering design" in contrast to any superstructure transportation building design "an architectural design".

Due to their complex structures, transportation systems and buildings require planning, organization, and collaboration among different design and engineering disciplines. Moreover, due to their intensive scales and effects on urban frameworks, debates over transportation buildings finds bigger audiences than architectural communities. Even by looking at the second half of the 19th century, one can see that train stations, railroads, and bridges turned into and inspiration points for artists like Monet, Manet, Cezanne, and more. In addition, it is also possible to see that transportation also influenced new ideas and manifestations in the history of architecture, such as the Italian futurists inspired by speed and mechanization (Banham, 1960).

\section{Aim of the Course}

Consequently, beginning from the 2019 Autumn semester, ARCD 110 Transit Architecture had been an intriguing elective course at the department of architecture at Abdullah Gül University (AGÜ). The class focuses on the complex nature of transportation buildings where designers have to deal with all the mandatory safety, accessibility, and operational design considerations along with the various design issues related to the nature of the design. As a result, the objectives of the course are shaped around the notions such as;

- Understanding the basic terminology

- Developing awareness to the international and national standards, design guidelines, principles, legislation, and other related texts followed by an interpretation and discussion of these materials

- Understanding the design approaches to the transit architecture both from technical and theoretical aspects.

- Understanding the impacts of transit building design on an urban scale.

- Developing a critical framework to the existing design methodologies in transit design.

\section{Class Structure}

The whole structure of the class is based on a linear approach (Figure 1). First of all, the basics of the infrastructure and the world of infrastructure design are introduced to the students so that they can have a base for the upcoming weeks and studies. As the article written by Meyboom (2009) highlights the design of infrastructure has the potential to create a place and propose future 
growth. Moreover, the article indicates that robust design approaches need to be developed to improve the existing architecture scale of the city. As a result, to explain the importance of connectivity, a history of transportation is presented, starting from the palaces of Assyrian kings to the Silk Road and subsequently to the current transportation networks. By doing so, one can understand the powerful notion of "being connected" and its crucial role in cities.

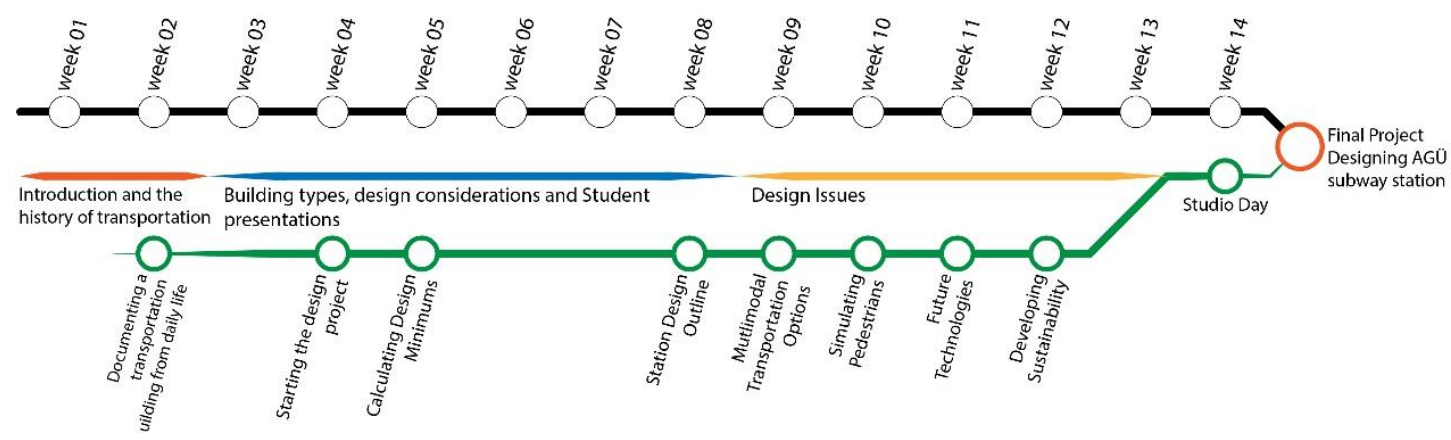

Page | 268

Figure 1 Class structure diagram showing the process of the whole semester (author)

\subsection{Typologies and Technical Design}

After setting the historical background and the basics of transportation, students are expected to document a transportation building from their daily lives and write down a building critique. The most common examples of this assignment are Kayseri tram stations and Kayseri intercity bus terminals in addition to some exciting buildings such as Bismil Diyarbakır-Turkey Bus Terminal, Syntagma Metro Station in Athens-Greece, and the Rapid Bus Transit stations of Dar es SalaamTanzania. The most common adjectives to define their perception about the buildings are circulations, form of the building, possible design decisions that they are not comfortable with, and most importantly, emotional spaces because it also represents a journey far from their homes. The main intention of this assignment is to provoke the students to realize that they are already aware of the problems of the current design approaches to the transit buildings. By doing so, the technical part of the class could also start with questions in mind. For a considerable series of weeks, students are introduced to different types of transportation buildings as in the order of train stations, metro stations, bus and rubber-wheeled vehicles, airports, and seaports. This order, aside from seaports, follows a historical progression. In order to shift the class from lecture series to a more participatory environment, every session starts with imagining the use of the building and the design of the building so that all can draw a map of the case studies. As an example, Figure 2 shows a pedestrian flow in a subway station case showing the movement scheme of pedestrians in a subway station.

This informative series start with the trains since the first examples of transportation where the vehicle was not powered/towed by livestock (1930ies to 1910s). Trains are followed by busses and personal cars (the 1910s to 1945s) where they developed new types of buildings in addition to the current design concerns such as walkable cities. Afterward, airports and their dynamics, along with their typologies, are inspected in the following week. Finally, different types of seaports among various cities and settings are inspected to understand the current nature of sea transportation. In addition to these technical aspects, every week also includes an associated design issue such as designing for accessibility, walkable cities, designing for vehicles and pedestrians. The main intention of these lectures and debates in this class focuses on the fact that transportation systems require intensive planning, organization, and collaboration among different design and engineering disciplines. 


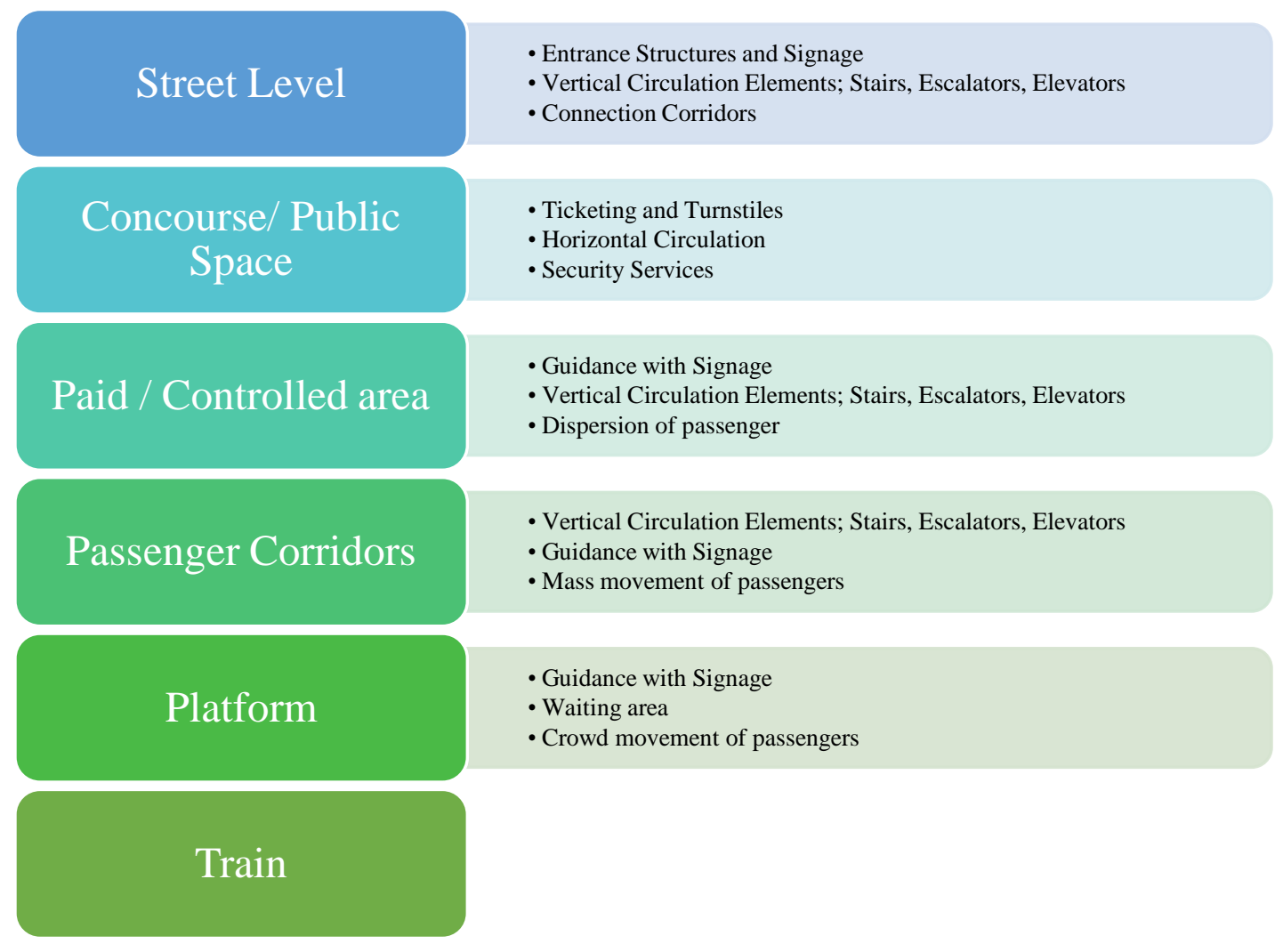

Figure 2 An example of a pedestrian flow in subway station case study showing the movement scheme of pedestrians in a subway station with stations zones stacked in order from the surface to the train along with the movement factors and assistants in the process (author)

One of the biggest challenges in the preparation period of this class defined the finals product and evaluation of the students. Instead of organizing a classical midterm and a final exam where students are expected to answer multiple questions in a limited time, a reproduction of the design process of a metro station is assigned as a final project of the class. Interestingly, Kayseri Ulaşım's future network studies helped us a lot in the process. As seen in Figure 3, one of their future extensions (green and red lines) is going to be located at Erkilet boulevard which divides AGÜ Sümer Campus into two (Kayseri Ulaşım, 2019). Consequently, this design challenge is located in front of the campus so that students can associate themselves with an urban context where they use it for the same purposes.

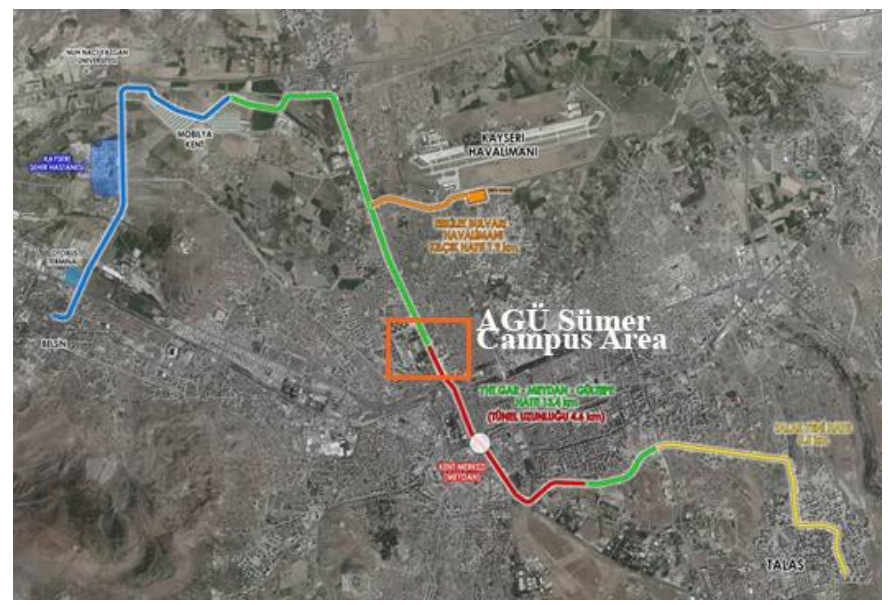

Figure 3 Satellite image showing AGÜ Sümer Campus location (orange rectangle) on Kayseri Ulaşım's future network map. (Author based on Kayseri Ulaşım's graphic) 
Besides, according to the same information, a transition from underground to the ground level is expected to be in front of the campus area. Therefore, instead of limiting the students to an underground solution, students are allowed to pick any station types for their design approach, such as at-the-grade and elevated (K W Griffin, 2004) as long as they separate the railway from pedestrian access for safety concerns.

Combined with the assignments during the semester, students can practice multiple aspects of a subway station process. As for the first step, they are expected to make some calculations based on the Turkish Standards TS 12127: Design Criteria for Underground Station Facilities (TSE, 1997a), TS 12186: Design Criteria for Ground Station Facilities (TSE, 1997b), and LUL G371a:2012 Station Planning Standards and Guidelines (Transport for London, 2012). As the example can be seen in Figure 4, the question aims to start the design process where an architect receives a transportation load from a transportation planner and start to process this information to their design. In a realtime experience, architects are expected to calculate the number of entry \& exit gates, the final number of gates, concourse area, number of tickets issuing windows and machines, staircase width, number of escalators, and total platform width depending on that load. In addition to calculating the same load with different calculation methods, they are expected to write a critique of the results and the documents. The comments of the students shaped around the difference between the personal space suggestions and the amount of detail between the standards and design guidelines.

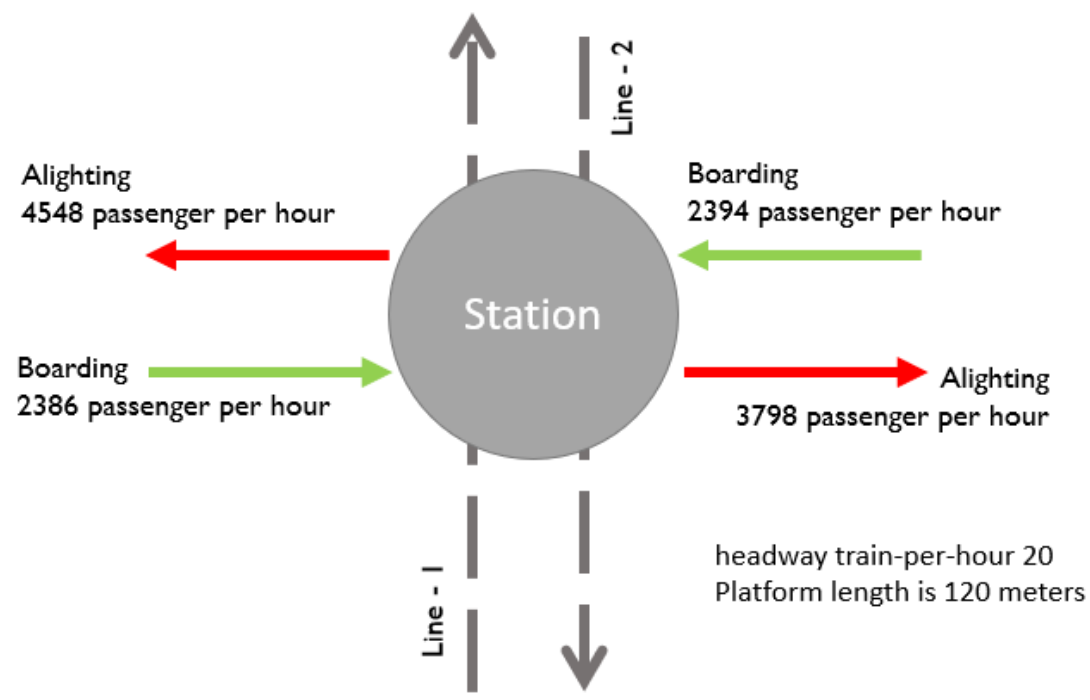

Figure 4 A typical passenger load question that starts the final project (author)

\subsection{Design Issues in Transportation Buildings}

As for the second part of the semester, various design concerns are debated in the class to develop a critical framework for the existing design methodologies. These debates include a wide range of views and issues from urban design, such as implementing multimodal transportation to the use of computer simulations as a design verification tool.

\subsubsection{Multimodal Transportation}

The first design issue that has been taken into consideration is the possibilities of multimodal transportations. According to Griffin (2004), the effective range of a subway station is could be 1 to 1.5 kilometers depending on the landscape. People can reach the station by different mediums of transportation such as; driving, cycling, and ridesharing in addition to walking. For bigger buildings, park and ride, kiss and ride, and bicycle amenities are also considered multimodal options 
(Queensland Government, 2015; Lang, 2017). In addition to multimodal solutions, a different scale of mobility called micro-mobility creates transportation possibilities that include bike-sharing, carsharing, scooter sharing, and e-bike sharing (Lazarus et al., 2020; Moran, Laa and Emberger, 2020; Shaheen et al., 2020). By doing so, pedestrians have increased accessibility in dense urban settings in a fast and efficient way. It is equally important to keep in mind that recent studies show that with policies such as bike-sharing and options, \%5.5 of the users sold or postponed a vehicle purchase, and $50 \%$ of the bike-sharing members reduced personal car usage (Shaheen et al., 2020). Especially during the pandemic, we see a shift from mass transportation systems to personal transportations methods (O'Sullivan, 2020). For example, the demand for bicycles have increased dramatically as an alternative transportation method (Landis-Hanley, 2020). In addition, demand for shared mobility solutions such as e-bike sharing, scooter rentals has also increased (Liu and Ren, 2020). As a result, multimodal transportation options and solutions are and will be an important part of transportation and the designers should be well aware of the situation. After looking at different design examples and debating these concerns, they are expected to develop a multimodal approach to their final project designs. Given that the station location is between the dormitories and the Sümer Campus area, the most common solutions for this approach are micro-mobility design approaches to increase the ease of access around the campus buildings.

\subsubsection{Personal Space as a Design Parameter}

Even at the early design stages of transportation buildings, personal space is one of the most significant design parameters for architects and fire safety designers. As mentioned above, with various design guidelines and standards, one can determine various parameters such as the width of platforms, corridors, number of escalators, and ticket machines. Subsequently, area per person is an important design parameter, yet we need to develop the dynamics and the inconsistencies of the definition.

According to Hall (1992), humans are territorial, and this behavior shapes their activities in groups. Moreover, he also mentions that people set distances among each other depending on their feelings to others. These distances are categorized into four groups; intimate distance, personal distance, social distance, and public distance. It is always too exciting to show the classroom dynamics and how they feel about each other while explaining these distances in a classroom environment. As a part of the education process, a single $1 \times 1$ square is drawn to the floor to test different design guidelines and standards (Figure 5). At first, while they were comfortable in overloaded scenarios with their familiar friends. However, after mixing up the populace, one can trace the body movements of keeping distance or creating some kind of protection (like crossed arms) in the crowd. As in the case of the subway stations, there different documents suggesting different areas per person. For example, while the Turkish standards suggest $0,50 \mathrm{~m} 2$ per passenger (TSE, 1997a, 1997b), American Public Transportation Association (APTA) recommends $0.765 \mathrm{~m} 2 \mathrm{per}$ passenger (1981), and according to LUL - G371A same parameter is considered $0.96 \mathrm{~m} 2$ per passenger(2012). Followed by different case studies such as the Kowloon Walled City and Calhoun's rat experiment in the Rockville barn, the primary intention of the week is to develop an understanding of personal space. By doing so that they can understand that the technical guidelines and standards related to the transportation buildings help the designers to find the design minimums of a case rather than defining a working terminal or a station. 

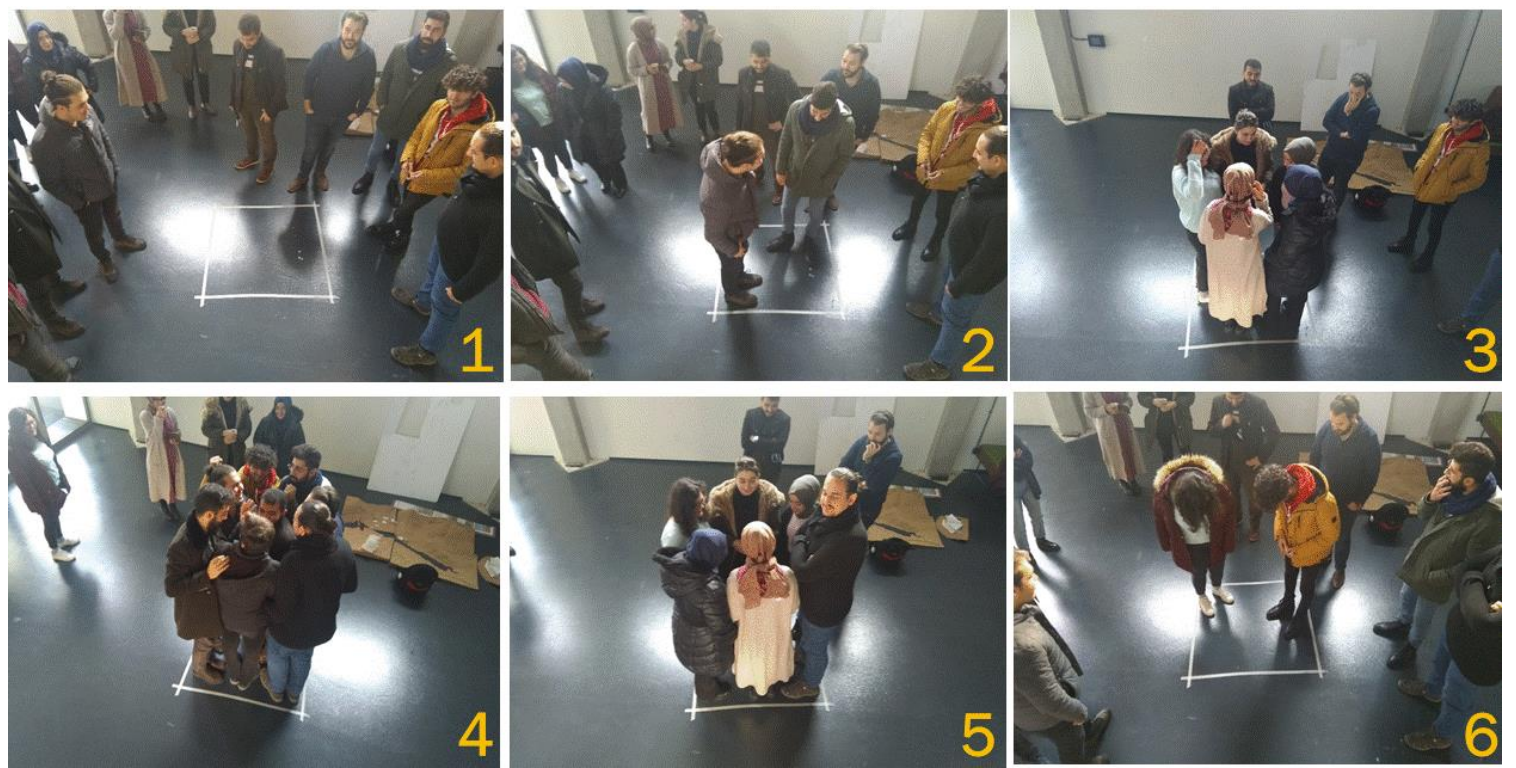

Page | 272

Figure 5 Personal space experiments where a $1 \times 1$ square is marked at the floor (1). Afterward, they start to test different loads such as the basic TS 12127 and TS 12186 load (2), crushing loads (3\&4) followed by different case studies (5\&6).

\subsubsection{Sustainability}

As the dictionary term of sustainability defines, one of the main goals of the profession should be meeting the needs of the present without compromising the ability of future generations to meet their needs(McCombs, 2015). In view of the fact that transportation buildings are designed with up to 50 years of future projections and used for 150 years if possible, creating a sustainable design in this building type becomes a vital design issue. However, developing an energy-efficient building could not be defined as sustainable due to the triple bottom line of sustainability. As a result, after a debate on creating sustainable transportation buildings from energy efficiency, economic and social aspects, students are expected to develop a design suggestion for their finals within the framework. The most common solutions for this design issued grouped around two interesting factors, daylight and restoring the station's location as a social node instead of being a transportation point.

Güneş highlights that the underground is associated with negative aspects such as misconduct, secrecy, the afterlife, and death (2007). Besides, one can see alternative solutions and suggestions to integrate daylight to overwhelm psychological, physiological, and energy efficiency problems (Carmody and Sterling, 1984, 1993; Sterling et al., 2012). However, despite the fact that two alternatives can be applied to provide daylight inside the station, skylights, and lightwells, none of the projects had suggested lightwells as a part of their design. This situation could also be related to the possibility of natural ventilation with the skylights in contrast to the skylights. On the other hand, various projects suggested multifunctional buildings where they have students' centers, shopping areas, libraries, and even an open-air marketplace for social and economic activities combined with their station design which should be taken into consideration.

\subsubsection{Pedestrian Simulations}

In addition to developing a critical view on the personal space, it is equally important to simulate a design case in a simulation so that one can test their buildings even at the early stages of the design. In view of the fact that simulation is the imitation of an existing situation or a process, a review of the pedestrian simulation types is presented so that a critical approach could be developed aside from experimenting with simulation software. The most known case is Fruin's Pedestrian Planning and Design(1971) and his level of service methodology, where he develops a 
system based on the number of passengers crossing a meter section of the selected area with the speed-flow-density relationship mentioned by Gupta and Pundir (2015). Subsequently, different types of pedestrian simulation systems are mentioned, such as Cellular Automata, Benefit-Cost, Magnetic Force, Social Force, Tactical Routing, and Agent-Based models as a background for the students.

As a class practice with a brief introduction to a selected pedestrian simulation software, students try a tutorial case where they can learn the basics of the software. Afterward, they test the early stages of their final project design and make any revisions if necessary. One of the key findings of the process is that this simulation study became aware of a design validation tool and helps them understand the importance of pedestrian circulation in any building design. In the future we hope to establish a cooperation between software firms and AGÜ so that students can work with these simulation tools for longer time periods and even develop future researches both at the undergraduate and graduate levels.

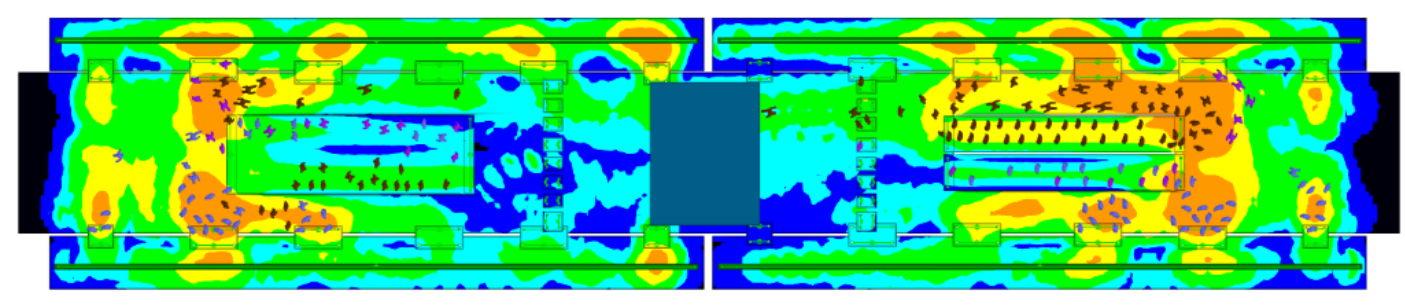

Figure 6 Simulation result of a station design where one can see the experienced density based on Fruin (1971)

\subsubsection{Predicting the Future}

Transportation buildings have changed dramatically in two centuries. While the first examples were simple and, in an attempt, to organize the much-needed functionality following examples have turned into monuments of prestige regardless of the vehicles they use. It is interesting to see how Negroponte (2000) anticipated the last twenty years on concepts such as the post-information age, place without space, and being asynchronous in addition to four powerful qualities; decentralizing, globalizing, harmonizing, and empowering. Primarily through our recent experience with the COVID-19 pandemic being digital has turned into an essential aspect of our life. In addition, with the recent developments in technologies, one can see that our means of transportation both on and from the earth will change in a short amount of time. New means of land transportation systems such as hyperloop (Street, 2019; Hawkins, 2020) show us that our fast, efficient, and economical means of transportation might change in the near future. Similarly, with the increased interest in space travel and interplanetary travel, we might even need to reconsider new types of transportation buildings for a design case. However, it is equally important to talk about these possible futures so that people can prepare new concepts for the existing design methods and approaches.

\section{Course Outputs and Final Projects}

The course outputs could be divided into two segments; findings from the student presentations and findings from the final design projects. The student presentation part is an interesting way to understand the perception of the students to the subject given the fact that the only limitation for their selection is that it should be a transportation building. On the other hand, by looking at the submitted final projects, it is fascinating to trace how different arguments and debates at the class helped them to improve their design capabilities both for this class and for their design studios 


\subsection{Student Presentations}

Students were expected to pick an existing transit building for their presentations. In the process they were required to prepare and share information about the building, its history, design approach, and its design process. Presentations are organized on the corresponding week of the building type. In order to increase collaboration and organization among the students, these presentations were group projects in the pre-pandemic era. However, due to increased difficulties of connection and preparations during the pandemic, it turned into personal presentations. Though, with the increased number of presentations, the variety of the case studies have dramatically improved. In the process, 29 different projects have been presented worldwide, showing different design cases such as design competitions, international firms in different settings, and renovation and expansion of historic buildings as a part of heritage preservation. Interestingly, the two buildings, Yokohama Passenger Port and Jewel Changi Airport, are the two most popular buildings which have been presented almost every semester.

The intended structure of the presentations focused on three aspects; the Building's story, its significance, and the presenters' comments. While the first part focuses on the literature review of the building, the second part aims to express a comprehensive assessment of the building from different resources. Lastly, the most essential part is making comments about the building as an architecture student. This structure brought forth very interesting debates to the class. These debates include concepts such as superficial use of local motifs by international architects to adjust their designs for varying tastes, local design firms vs. international design firms, awards in architecture, and the power of symbolism in architecture. Thus, these debates helped them to progress their design approaches for their future studies and experiences.

\subsection{Final Projects}

As mentioned above, the final evaluation of the class is the design of a subway station in the given location instead of a written final exam. In order to increase awareness of the urban design concerns of transportation buildings, the site of the project on the line crossing the campus is on Erkilet boulevard. While the students were free to pick any type of station (at-the-grade, elevated or underground), they were also expected to develop their design based on the issues mentioned at the design issues weeks. Interestingly, a considerable part of the class, \%76 percent, have decided to design an underground station in contrast to elevated and at-the-grade solutions. In addition, while the students from different departments have taken the class, they are encouraged to develop a design to the existing infrastructure or building design from their own field of education.

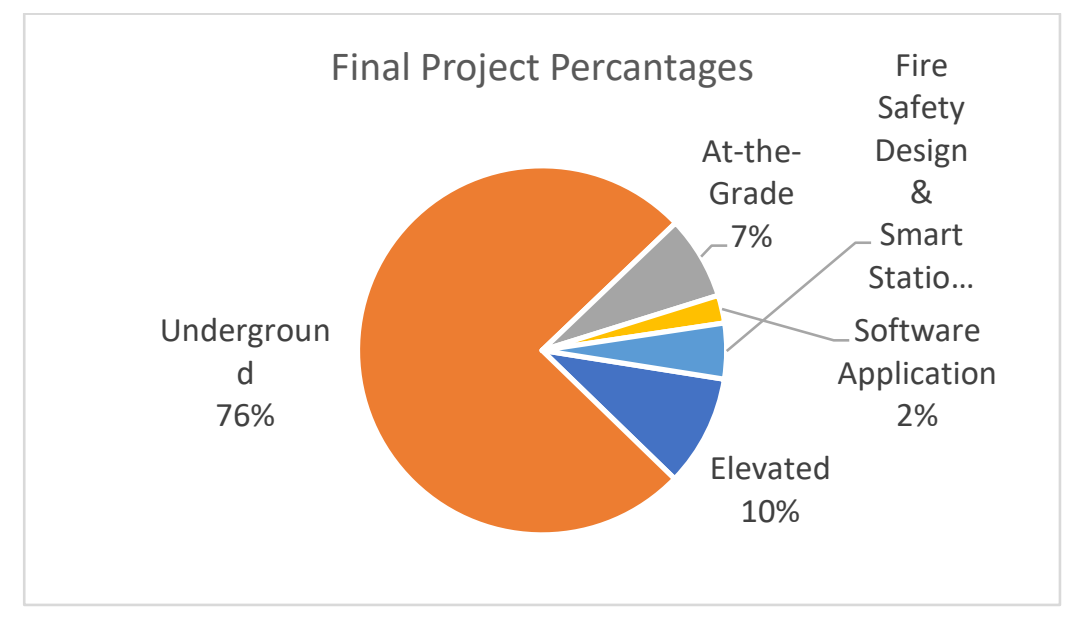

Figure 7 Percentiles of submitted projects and their typology (author) 
Among the interesting design suggestions, one can see that they have also provided some valuable information for the future of the AGÜ Sümer campus area. A considerable part of the designs suggested moving Erkilet boulevard underground and the railway line to give back the area to the pedestrians with green spaces. This approach could be interpreted as an attempt to remove the barrier between the two parts of the campus and the surrounding neighborhoods. One example can be seen in Figure 8, yet one can also see alternatives of this design approach where the whole campus area is connected with similar design suggestions. In contrast, we can also see alternative underground design solutions suggesting reorganizing the whole traffic at different levels while providing pedestrian access at the ground level, as seen in Figure 9. The vital part of these designs shows us that at the daily activities of the campus, while Erkilet boulevard plays a crucial role as the transportation path, it also acts as a significant barrier dividing the campus.

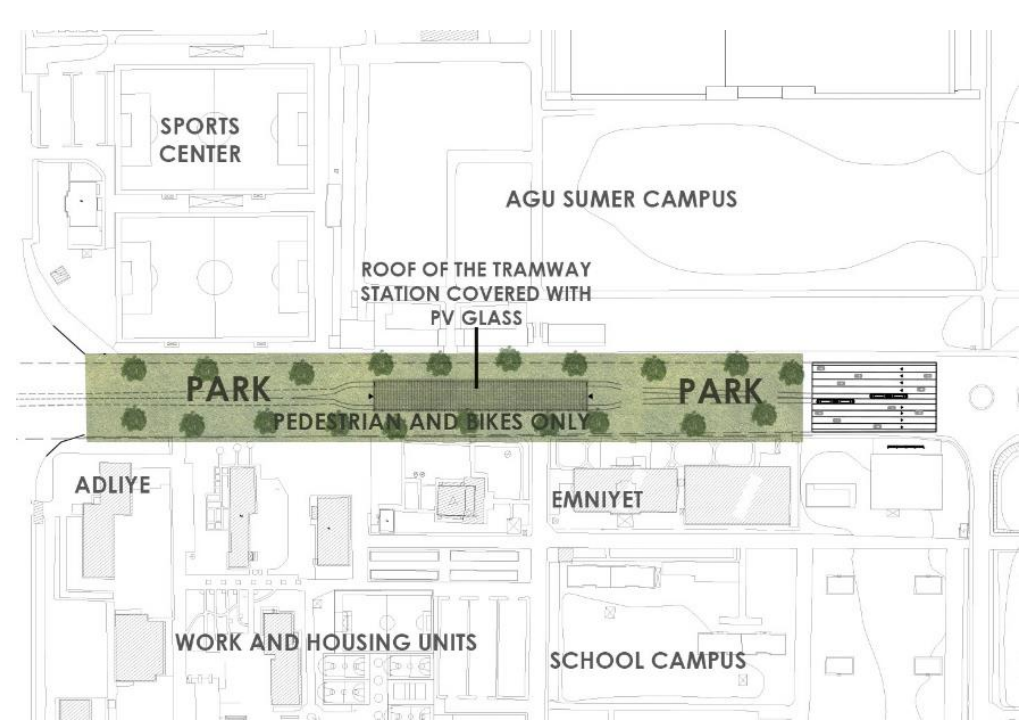

Figure 8 Site plan of a station design suggesting to move Erkilet Boulevard underground. (Berfin Nur Şahin)

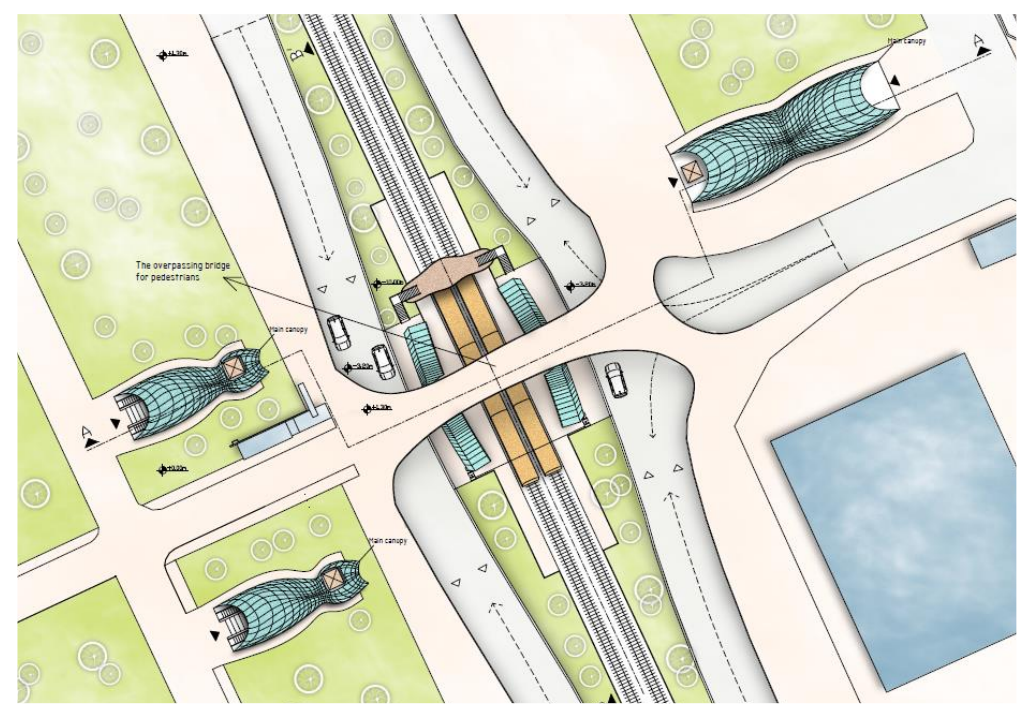

Figure 9 An alternative design solution where the designer suggested a multilayer solution; pedestrian on the ground, vehicle in the middle, and the railway system at the bottom. Yet, with a landscape design, it is also possible to provide daylight to every level of the station (Oruç Türk).

In addition, by adding functions such as student centers, educational facilities, stores, and exhibition halls, it is possible to see that students wanted to create an interface between the public 
and the campus. These design concerns could be related to the existing design suggestions developed by Asiliskender and Yöney (2018) for the AGÜ campus. As seen in Figure 10, some of the designs suggested spaces such as new centers and experiences along with the station structure.

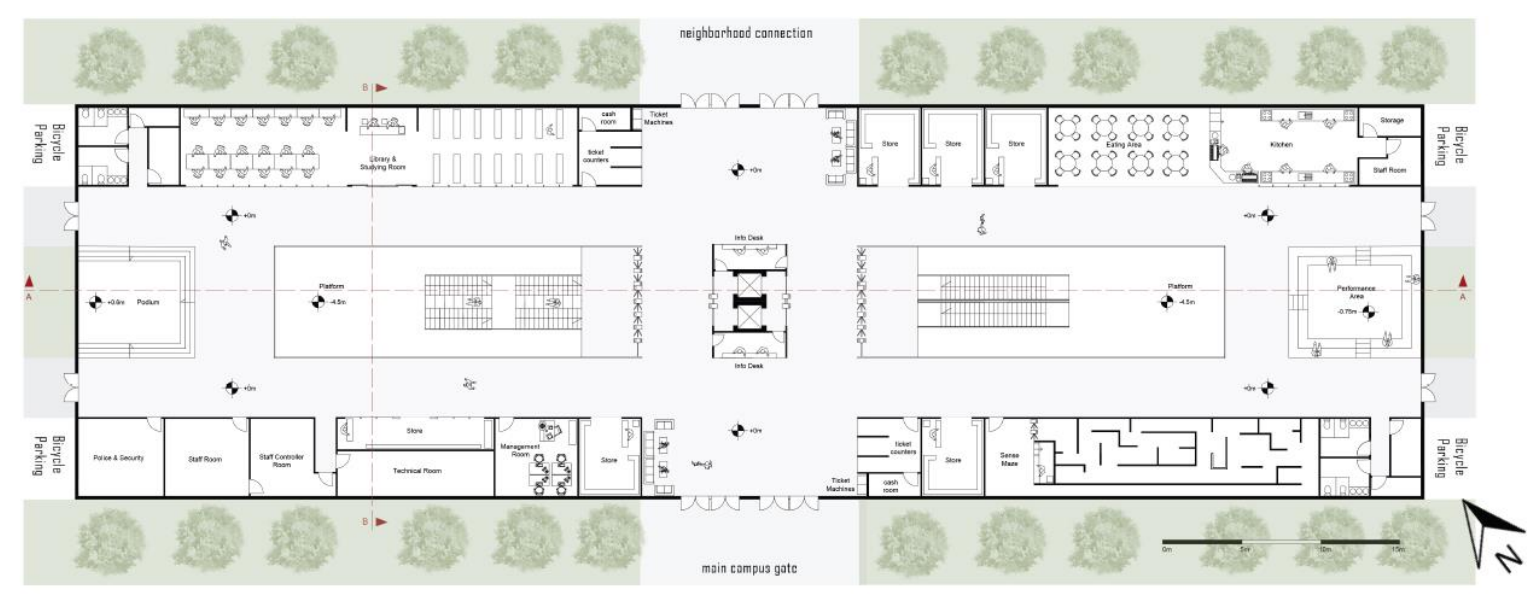

Figure 10 Design suggestion where the designer suggested a micro-mobility center research for the city with research areas and interactive surfaces (Görkem Kemal Genç)

On the other hand, when looked at the elevated and at-the-grade designs, form-finding procedures focus on two design concerns; providing accessibility over Erkilet boulevard and creating a platform as a viewpoint at the city. As seen in Figure 11, the main challenge of this approach is to deal with the massive columns supporting the station structure at the road level. Like the underground designs, there are additional functions providing services to the public and the campus area. Nevertheless, by being over the ground, they had the chance of being visible and exterior to other people aside from its services, and some of the designs have successfully achieved that intention.

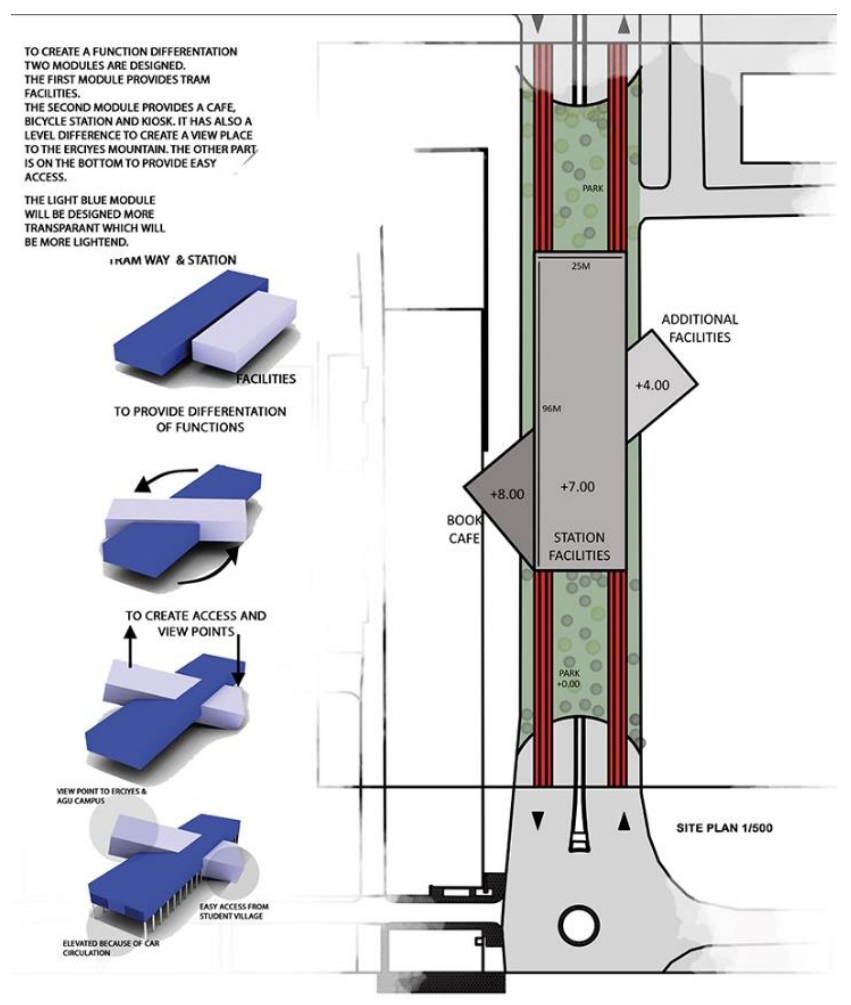

Figure 11 From finding process and the site plan of a design suggestion (Hilal Sevim) 
A computer engineering student developed another noteworthy design approach as a final project. After enrolling in the class, it would be unfair to ask a computer engineering student to design a station. Therefore, with the consent of the rest of the class, the project took a dramatic turn, and a mobile phone application is designed for Kayseri Ulaşım within the framework of smart cities, internet-of-things, and mobility. The main intention of the application was to gather live statistics about the users' preferences and experiences to the operating firm while providing information about the existing situation of the transportation network. For example, users can find the nearest ticketing machines, access information about the traffic density, see the live situation of the station, access information about the network, and give feedback about their recent trips (Figure 12). This example stands as an important indicator that shows us that developing a critical view on the existing design methods not only will help the architecture-related disciplines but also will help other disciplines to question their own design approach to improve their design methodologies.

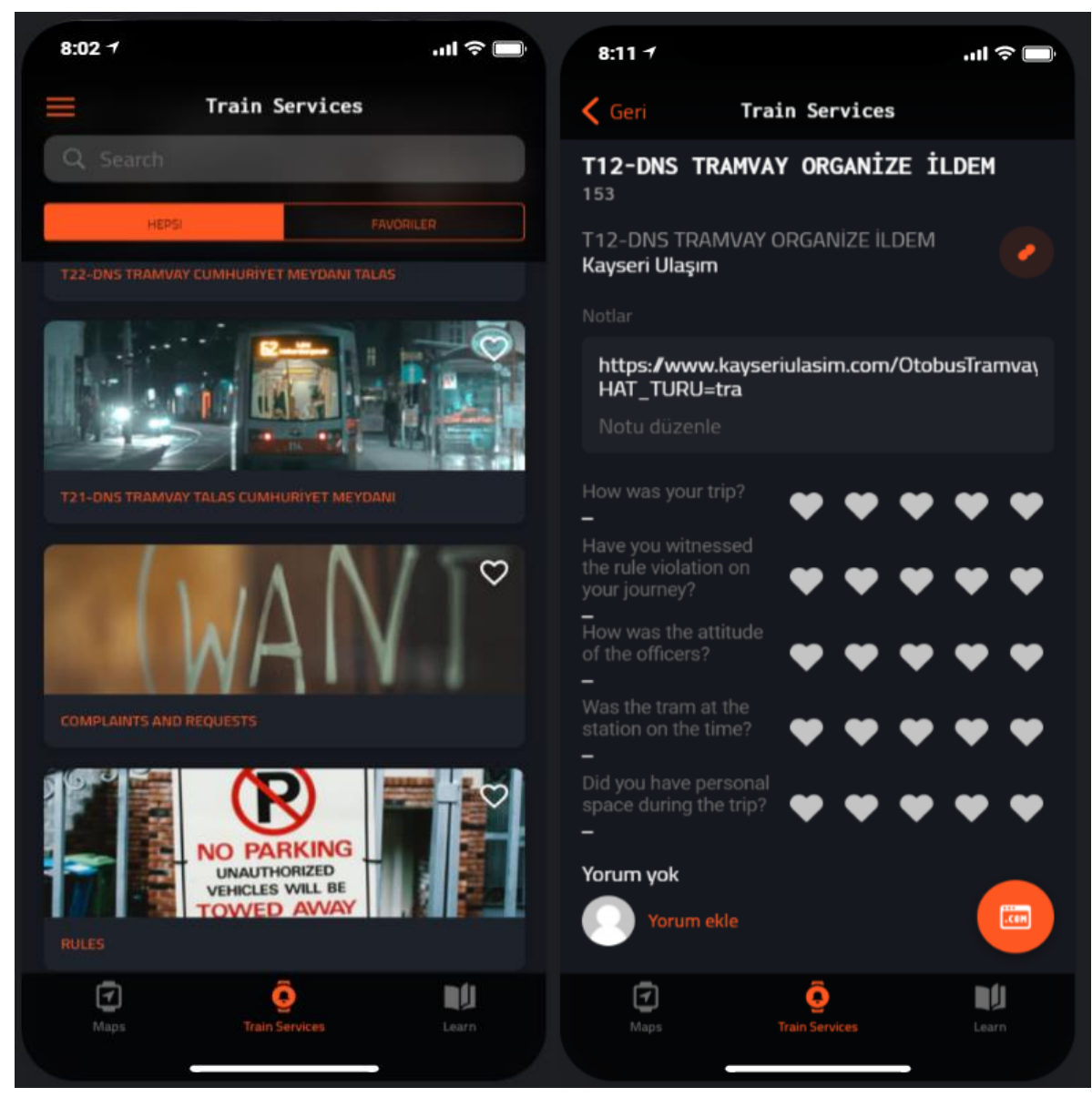

Figure 12 Screens of the application showing the travel query questions (Sedanur Aslan)

\section{Conclusions}

ARCD 110 Transit Architecture class has begun with a combination of both professional and academic questions developed after a long process started in 2013. From an architectural perspective, infrastructure and related buildings are considered dull and monotonous because of their repetitive nature. This repetitive nature could be related to various aspects such as monetary restrictions, project management concerns and, limited timeframes. However, it is important to keep in mind the vital relationship between instrumentality and function in infrastructural projects. Interestingly, while the train stations and airports are regarded as important and prestigious 
showcases acting like landmarks and monumental gateways with commemorating names after leaders, artists, scientists, and writers. One can hardly trace any similar approach at inner-city transportation buildings because they are considered as recurring engineering buildings shaped by engineering concerns despite their crucial impacts on urban scales. This situation is mainly associated with the prescriptive methods suggested by design guidelines and standards in transportation buildings. Yet, one can see similar repetitive design solutions at hospitals, hospitality buildings, tall buildings, dormitories, and offices. However, with their urban potentials, transportation buildings highlight that questioning the existing design problems and acceptances became more important than ever before the pandemic because the existing problems and concerns were already identified and addressed before. As a result, while the first part of ARCD 110 highlights the multidisciplinary design concerns in various transportation buildings followed by the architectural design concerns that should take into consideration. In the process, they also experience the design process of a subway station in a familiar urban context so that they establish their urban analyses to understand the importance of such a design process. Besides, with the ongoing urbanization where most of the human population living in the cities and the global warming concerns, we need to study transportation buildings not only for their building performance analysis or fire safety design studies but also their impact on architectural design.

Therefore, in order to understand the current situation of the transportation buildings from an architectural point of view and develop an awareness for future studies ARCD 110 Transit Architecture stands as an important first step at the undergraduate level both inspiring new studies related to the topic both at the undergraduate and graduate educations. In the near future, we are expecting to share these findings with the Kayseri Transportation Department to establish future cooperation with the AGU Faculty of Architecture.

\section{References}

Allen, S. (1991) Points + Lines: Diagrams and Projects for the City, Urban Patterns and Meanings Through History, London. New York City,NY, NY: Princeton Architectural Press (Architecture, urban studies). doi: 10.1002/ad.1821.

American Public Transit Association. Rail Transit Committee.; Transit Development Corporation. (1981) Guidelines for design of rapid transit facilities. Washington, D.C.: APTA.

Asiliskender, B. and Yöney, N. B. (2018) 'Fabrikadan Üniversite Kampüsüne; AGÜ Sümer Kampüsü', in GÜNER, H. E. (ed.) Süper Kent Kayseri. Kayseri, pp. 5-14.

Banham, R. (1960) Theory and Design in the First Machine Age. 2nd edn. Massachusetts: The MIT Press.

Blow, C. J. (2005) Transport terminals and modal interchanges: planning and design. Oxford: Architectural Press.

English, J. (2019) The Commuting Principle That Shaped Urban History CityLab. Available at: https://www.citylab.com/transportation/2019/08/commute-time-city-size-transportation-urbanplanning-history/597055/ (Accessed: 7 October 2019).

Fruin, J. J. (1971) Pedestrian Planning and Design. 2nd edn. New York, NY: Metropolitan Association of Urban Designers and Environmental Planners, Inc. Available at: https://books.google.com.tr/books?id=vrckAQAAMAAJ.

Griffin, Kenneth W. (2004) Building type basics for transit facilities. Hoboken, New Jersey: John Wiley \& Sons (Building type basics series).

Griffin, K W (2004) 'Station Types and Configurations', in Building type basics for transit facilities. Hoboken, New Jersey: John Wiley \& Sons (Building type basics series), pp. 63-80.

Gupta, A. and Pundir, N. (2015) 'Pedestrian Flow Characteristics Studies: A Review', Transport Reviews. Routledge, 35(4), pp. 445-465. doi: 10.1080/01441647.2015.1017866.

Hall, E. T. (1992) The Hidden Dimension. Anchor Books. Available at: https://books.google.com.tr/books?id=HImqAAAACAAJ. 
Hawkins, A. J. (2020) Virgin Hyperloop hits an important milestone: the first human passenger test - The Verge. Available at: https://www.theverge.com/2020/11/8/21553014/virgin-hyperloop-first-human-testspeed-pod-tube (Accessed: 24 April 2021).

Kayseri Ulaşım (2019) Yeni Raylı Sistem Hatları. Available at: https://www.kayseriulasim.com/tr/kayseriulasim/yeni-rayli-sistem-hatlari (Accessed: 18 April 2021).

Landis-Hanley, U. (2020) 'Bicycles are the new toilet paper': bike sales boom as coronavirus lockdown residents crave exercise, The Guardian. Available at: https://www.theguardian.com/lifeandstyle/2020/apr/22/bicycles-are-the-new-toilet-paper-bike-salesboom-as-coronavirus-lockdown-residents-crave-exercise (Accessed: 3 June 2020).

Lang, J. T. (2017) Urban design : a typology of procedures and products : illustrated with over 50 case studies. New York: Routledge.

Lazarus, J. et al. (2020) 'Micromobility evolution and expansion: Understanding how docked and dockless bikesharing models complement and compete - A case study of San Francisco', Journal of Transport Geography, 84, p. 102620. doi: https://doi.org/10.1016/j.jtrangeo.2019.102620.

Liu, R. and Ren, S. (2020) 'Chinese Cities Today: Modal Shifts \& Private Sector Responses', 28 May.

Lynch, K. (1960) The Image of the City. Harvard U.P.; Oxford U.P (Harvard-MIT Joint Center for Urban Studies Series). Available at: https://books.google.com.tr/books?id=_phRPWsSpAgC.

McCombs, H. C. (2015) LEED Green Associate exam preparation guide, LEED v4 edition.

Meyboom, A. (2009) 'Infrastructure as Practice', Journal of Architectural Education (1984-). Taylor \& Francis, Ltd., Association of Collegiate Schools of Architecture, Inc., 62(4), pp. 72-81. Available at: http://www.jstor.org/stable/40481065.

Moran, M. E., Laa, B. and Emberger, G. (2020) 'Six scooter operators, six maps: Spatial coverage and regulation of micromobility in Vienna, Austria', Case Studies on Transport Policy, 8(2), pp. 658-671. doi: https://doi.org/10.1016/j.cstp.2020.03.001.

Negroponte, N. (2000) 'Digital Life', in Being digital. New York: Knopf, pp. 163-231.

O'Sullivan, F. (2020) 'Londoners Have Become Afraid of Public Transit', Bloomberg CityLab, 12 June. Available at: https://www.bloomberg.com/news/articles/2020-06-12/fear-of-public-transit-remains-high-inlondon

Queensland Government (2015) Public Transport Infrastructure Manual (PTIM) 2015. Brisbane: Department of Transport and Main Roads - TransLink Division.

Shaheen, S. et al. (2020) 'Chapter 13 - Sharing strategies: carsharing, shared micromobility (bikesharing and scooter sharing), transportation network companies, microtransit, and other innovative mobility modes', in Deakin Land Use, and Environmental Planning, E. B. T.-T. (ed.). Elsevier, pp. 237-262. doi: https://doi.org/10.1016/B978-0-12-815167-9.00013-X.

Street, F. (2019) How long until Hyperloop is here? I CNN Travel. Available at: https://edition.cnn.com/travel/article/how-long-hyperloop/index.html (Accessed: 24 April 2021).

Transport for London (2012) LUL - G371A Station Planning Standards and Guidelines. London.

TSE (1997a) 'TS 12127: Şehir içi yollar-Raylı taşıma sistemleri Bölüm 1: Yer altı istasyon tesisleri tasarım kuralları'. Ankara: TSE, p. 32.

TSE (1997b) 'TS 12186 Şehir içi yollar-Raylı taşıma sistemleri, Bölüm 2: Yer üstü istasyon tesisleri tasarım kuralları'. Ankara: TSE, p. 27.

\section{Resume}

Özgür Öztürk is a part-time lecturer at Abdullah Gül University, Department of Architecture. He received his bachelor's degree in architecture from Istanbul Technical University (2008); his master's degree in History of Architecture from Middle East Technical University (2011); and his Ph.D. degree in Architecture at Middle East Technical University (2020). In the meantime, he also practiced as an architect in various design and engineering firms especially at numerous transportation-related buildings both national and international projects at various scales. Still, he is practicing as the Lead Architect of Geodata S.p.A. Turkey Branch where he is responsible for the design and construction of subway lines in various Turkish cities. 